\title{
Supply Chain Choices
}

\section{Models of Supply Chain Integration}

Ever since the publication of Porter's seminal book Competitive Strategy, companies have become concerned with integration operations and their supply chain choices. ${ }^{1}$ Should a company remain in manufacturing, and how far backward or forward should a company be integrated? Both are questions that management practitioners debate. The same applies to the management of the supply chain; to what extent can a company rely on suppliers for raw materials, parts, and components? As a result, the practices of the SME sample companies have been analyzed in light of these questions, in order to see whether there are any discernible patterns.

Of the 36 companies researched, all but 2 (u-blox and Jura) directly engaged in manufacturing to varying degrees. That means these companies all owned manufacturing assets, some of which might be located outside of Switzerland. For the purpose of this section, any manufacturing assets, owned anywhere, were taken as an indicator of manufacturing activity.

The extent of being involved in manufacturing stretched from fully integrated operations to assembly only, with some companies in the mid-range of integration employing a mix of activities. For the purpose of this analysis, it was therefore differentiated between the following categories (the authors' own terminology):

- The Integrators

- The Partial Integrators

- The Assemblers

- The Outsourcers/Fabless

\footnotetext{
${ }^{1}$ Porter ME (1980) Competitive strategy. Free Press, New York. 
Depending upon the extent of manufacturing integration, the companies also used their sourcing strategies for components, or subassemblies, to hedge against currency risks.

\section{The Integrators}

SMEs who operated in a fully integrated mode, covering all major steps of the manufacturing process internally, could be found in various industries. They included those firms attached to primary resources from agricultures, or other resources difficult to access, as well manufacturing companies with unique processes.

Early in its history, Ricola, the producer of herbal drops, expanded up the value chain as a way to ensure its supply of herbs, the key raw material for its products. The backward integration into herbs also impacted the logistics of warehousing and storage at the company's processing center in Laufen.

By the early 1980s, the success of Ricola sales began to outstrip its supply of herbs, which up to that time came mostly from the local area. The company launched an appeal to Swiss communities and schools, with disappointing results. Eventually the company connected with over 100 contract herbal farmers in the Swiss Jura and mountains, encouraging them to plant the herbs on contract. Ricola provided the seeds to the farmers. The total plantation area amounted to an equivalent of about 124 football fields and yielded 1,400 tons of fresh herbs each year. Herbs were dried immediately in the various mountain regions, then put in bags and shipped to the Ricola herb center for further sorting, drying, cleaning, and mixing with other ingredients. Each year, Ricola processed about 250 tons of dried herbs. ${ }^{2}$

Equally involved into sourcing its raw material was Felchlin, the chocolate couverture producer. This involvement was central to the company's strategy that relied to a large extent on processing selective cocoa beans not otherwise available on the world market. Felchlin's differentiation from major competitors rested on this practice.

Traditionally, the industry had treated all cocoa beans as being the same, essentially as a commodity. Aschwanden and his team at Felchlin decided to take a page out of other industries and develop a chocolate product line made from distinct, labeled and identified beans, such as was the case in the coffee industry. The Felchlin team went back to the roots of cocoa to identify special growers in South America who were small-lot farmers organized into cooperatives. This avoided the child labor issues, and Felchlin paid 10 percent above going fair trade prices. The resulting Grand Cru Selection consisted of single origin couverture, similar to single malt spirits. ${ }^{3}$

\footnotetext{
${ }^{2}$ Adapted from Ricola company profile.

${ }^{3}$ Adapted from Felchlin company profile.
} 
Although sourcing was important, it was not sufficient for Felchlin's competitiveness. The manufacturing process, too, had to be designed and controlled to guarantee the right product composition and consistency.

\begin{abstract}
All processing steps to arrive at the chocolate were made by Felchlin in its fully owned operation. Cleaning, roasting, milling, kneading, rolling and conching were the steps performed internally to meet the highest levels of fineness. Milk was sourced from the special UNESCO biosphere Entlebuch in Switzerland. After the expansion of the cocoa bean roasting facility in 2012, Felchlin began the process of planning and constructing an additional building that allowed for the entire company to be located on a single site. Felchlin planned to vacate older buildings to move next to the Ibach site. Management considered proximity and close communication to be of special value for a small business. The investment of the last building expansion was budgeted at CHF 20 million. ${ }^{4}$
\end{abstract}

Geistlich, the pharmaceutical company producing bone substitutes from natural materials, also found itself in a situation where control of the raw material was central, and the follow-on processing dictated a completely integrated manufacturing process.

At Geistlich, the production processes for a biomaterials company differed radically from the previous industrial production model. Careful selection of bovine bones was required, and bone or collagen was sourced exclusively from monitored establishments. Highly effective cleaning and purification processes were installed. The production processes were subject to regular inspections by various independent institutions and government authorities. End products were subjected to meticulous sterilization in sterile pressure chambers, not only for manufacturing but also for packaging. All products underwent individual manual quality control at the Swiss plant. This clean room environment differed radically from the environment of the old bone processing plants. The Geistlich manufacturing process established for the purpose of entering biomaterials was enhanced through complete in-house integration of all important process steps, as well as the accumulation of a large number of patents that were granted on its original products. The combination of these approaches made it very difficult for potential competitors to enter this space and was a prime reason why Geistlich could achieve dominance in this field. ${ }^{5}$

Among the manufacturers, Felco was an example of a completely integrated manufacturing company with most production steps being controlled internally.

Felco followed the policy of bringing key production steps in-house. As part of this strategy, Felco became the sole shareholder of Prétat in 1997, the only company specializing in aluminium forgings in Switzerland. Since nearly all Felco products came with forged aluminium handles, the acquisition of Prétat was of great strategic value. Prétat did half of its business as a captive supplier to Felco. The rest was with other customers, many of them outside of Switzerland. The company was founded in 1947 and had about 65 employees. ${ }^{6}$

\footnotetext{
${ }^{4}$ Ibid.

${ }^{5}$ Adapted from Geistlich company profile.

${ }^{6}$ Adapted from Felco company profile.
} 
A high degree of integration was maintained among most of the manufacturing companies. Some, such as DC Swiss, Fraisa, or Medartis, would acquire raw materials and produce the final product in-house. There the raw materials were more of a standard type, such as different metals or types of steel, that were available on the open market. Differentiation was accomplished through the conversion into the final product, not so much from unique source materials.

\section{The Partial Integrators}

Several companies pursued a mix of sourcing versus self-production, insourcing semi-manufactured parts, and combining this with manufacturing the critical elements. In the case of these firms, differentiation was gained from preserving the difficult steps in manufacturing key components internally. The examples of Rüger and Sylvac are highlighted below.

The Rüeger product line expanded considerably beyond its original temperature gauges. To the bimetallic temperature gages were added gas thermometers, HVAC temperature gauges, thermometers for marine diesel applications and thermo wells. More complex products added were temperature probes with transmitters, or multipoint sensors for use in many types of reactors. Temperature gauges represented more than 80 percent of company sales. Related to temperature instruments was a line of pressure gauges. And finally, the company also produced instruments on an OEM basis used mostly in the food industry. All of those products leveraged Rüeger's core technology. In its application space, Rüeger offered one of the most extensive and differentiated product lines. Some of these products were manufactured in large volume on automated or robotized lines, which allowed them to be produced in Switzerland. ${ }^{7}$

Sylvac had moved to insourcing basic caliper blanks from abroad to perform the more difficult finishing tasks, including mounting electronics, internally.

Concerning Sylvac's calipers products line, the company sourced blank calipers and finished them. Given that the new rules surrounding Swiss-made required that 60 percent of the value-added, exclusive of R\&D input (S/W), originated from Switzerland, Sylvac had to change its documentation for the calipers' product line. According to management, all catalogs had to be changed to eliminate the Swiss flag. Since the company image remained Swiss, this was not viewed as a big problem in marketing. ${ }^{8}$

Plumettaz produced in Switzerland and sourced most components locally. However, the Chinese sales subsidiary was also a source for some components produced in China, a practice that had been pursued by other companies as well.

Plumettaz's production facility and equipment was constantly updated and increasingly automation was used to remain efficient with a relatively complex product line. Most

\footnotetext{
${ }^{7}$ Adapted from Rüeger company profile.

${ }^{8}$ Adapted from Sylvac company profile.
} 
production and sourcing were concentrated in Switzerland, with the Chinese subsidiary assisting in the sourcing of some components. ${ }^{9}$

Even when a production was completely moved abroad, as was the case for Datamars, the presence of a fully integrated manufacturing operation offered a competitive advantage. With the permanent expansion to Asia, Datamars became the only vertically integrated company designing and producing all key components of RFID solutions for the companion animal and textile identification markets.

\title{
The Assemblers
}

A few companies are specialized in the assembly stage of their operations, sourcing key components from a large number of local, sometimes international, suppliers. These companies sourced engineered parts or components, made to specifications of their own design, from extensive networks of suppliers. Both Thermoplan and EAO were following this strategy.

\begin{abstract}
When Thermoplan was ramping up logistics, and production required to meet Starbucks' massive orders of thousands of coffee machines annually, the company benefited from its sourcing strategy. From its inception, the company had relied on local suppliers in Switzerland for its components, made to specifications as per Thermoplan engineering designs. Value chain activities at Thermoplan concentrated on purchasing components, assembly of machines, quality assurance and distribution via distributors, as more than 90 percent of its sales went into exports. ${ }^{10}$
\end{abstract}

The benefit of Thermoplan's strategy to concentrate on assembly only resulted in a more flexible production system in terms of volume, in addition to reducing the investments required to ramp up.

Within five years of receiving the Starbucks contract, Thermoplan sales had passed CHF 80 million and employment reached 130. By 2008, sales had doubled again to reach about 150 million and employment surpassed 200. Headcount of dedicated staff at component supplier companies were estimated to have surpassed 300. The level of 20,000 annual machines sold was reached in $2013 .{ }^{11}$

To protect its proprietary designs for its coffee machines, Thermoplan controlled component design. The company achieved a significant degree of protection in terms of its competitive advantage, which rested on design and construction but not a particular manufacturing process.

Thermoplan constantly adapted its production system. The entire logistics system was fully automated. Difficult and complex to manage, the production system and machine design had

\footnotetext{
${ }^{9}$ Adapted from Plumettaz company profile.

${ }^{10}$ Adapted from Thermoplan company profile.

${ }^{11}$ Ibid.
} 
to be re-engineered for lower cost. For management, it was important to keep assembly and production in Switzerland as quality advantages outweighed potential cost disadvantages. Thermoplan could claim Swiss quality and Swiss made for its equipment. For OEM partner machines, the name Thermoplan did not appear, only the Swiss cross did. As sales grew, Thermoplan had to continuously enlarge its production capacity. In 2005, the company broke ground for its third factory expansion. In 2014, came the fourth factory expansion and an additional 50 jobs. A major logistics center was planned for $2020 .{ }^{12}$

EAO followed a similar strategy of concentrating on downstream activities while tightly controlling the costs and quality of its supply network.

The large number of elements at the basis of EAO's modularized product platform with almost unlimited combinations required a dedicated value chain in line with the product line configurations. EAO did not produce its own plastic injection molding and metal stamping components. Instead, the company focused on four core value generators, on (1) product development with customers, (2) a dedicated expert supplier network, (3) automated assembling with in-line quality testing and (4) its worldwide sales and customer service network. The product parts were sourced from specialized suppliers, the majority from Switzerland or Germany. The all-important plastic components were sourced from Swiss injection molders. As a heavy user of tools and molds needed for its plastic material converters, EAO owned most molding tools, stored with suppliers for their use. Transferring these tools abroad would be slow. Consequently, plastic conversion operations and mold suppliers were largely based in Switzerland. ${ }^{13}$

The aircraft manufacturer Pilatus could also be categorized, to a large extent, as an Assembler. What mattered in the case of Pilatus was the fact that key components, such as avionics or aircraft engines, were sourced from USD currency-denominated suppliers, the USA in particular, providing a partial hedge in the case of the all-important CHF versus USD currency valuations.

Pilatus: Over the years, as the Swiss Franc began its steady rise compared to the USD or the Euro, the company maintained a considerable sourcing operation from local suppliers and subjected parts to a rigorous cost reduction engineering process. The sourcing of avionics systems and engines from North America helped partially with the currency exchange pressure. ${ }^{14}$

What is noteworthy for the Assemblers is their emphasis on exclusively engineered, designed, and quality controlled in sourced components, as well as on marketing and sales activities.

\footnotetext{
${ }^{12}$ ibid.

${ }^{13}$ Adapted from EAO company profile.

${ }^{14}$ Adapted from Pilatus company profile.
} 


\title{
The Fabless Two
}

Two of the researched companies, Jura and u-blox, did not own any manufacturing or even assembly facilities. Instead, they have outsourced this activity to a third party. In many ways, their business systems are similar to that of the Assemblers, except that they do not engage in assembly activities. The starting point for the two differs, but the end result is the same.

At u-blox, the company never did have any manufacturing capability and always had to source its products from external suppliers, as was covered in a previous section.

u-blox did not produce any chips or modules. Chips were designed by u-blox and sourced from several fabs in different Far East locations. They were shipped to an integrator company, Flextronics, in Graz (Austria) for final assembly and direct shipment to OEM customers. The role of u-blox was to design all products and to ensure quality. The company had designed its own quality control methodology, testing 100 percent of the output. Full traceability of manufacturers and suppliers were arranged to manage any kind of risk, political or otherwise. A dedicated supply chain unit was operating from the company's location in Thalwil, Switzerland. ${ }^{15}$

Several elements of Jura's business strategy were instrumental in achieving rapid a growth and global expansion. Examining the key elements that contributed most to Jura's success, the observer is struck by the company's focus approach which took place at several levels, from the product line, the marketing segment, the value chain, its branding strategy, its innovation approach and its sales and service models. In each of these areas, the company could be observed focusing further on particular subtasks within each element. A brief explanation of this process follows.

\begin{abstract}
Jura CEO Probst was fond of saying that No one can possibly run the entire distance alone and expect to reach their goal. There are runners for every stage of the journey. Using this analogy for Jura, he concluded that the company could not, on its own, design and launch a new line of espresso machines while at the same time ramping up production. As a result, Jura entrusted the production of its new automatic espresso machines to a partner, Frismag, located in Eastern Switzerland, to become its exclusive contract supplier. But, supplier only, as product design and downstream marketing strategy remained the full responsibility of Jura and its staff. Frismag, a company larger than Jura with more than 2,000 employees, was shouldering the entire production capacity investment leaving Jura to use its resources for the downstream steps of its value chain. ${ }^{16}$
\end{abstract}

Delegating the production of its espresso machines, Jura could concentrate on the key steps of the value chain it considers most important and for which the company had both the talent and the resources: design and downstream marketing.

\footnotetext{
${ }^{15}$ Adapted from u-blox profile.

${ }^{16}$ Adapted from Jura company profile.
} 
All features of Jura machines originated, were controlled and driven by the company. Its $\mathrm{CEO}$, Probst, played the leading role in this process as he frequently travelled to international sites. He was fond of visiting automobile shows and he appears to be influenced by modern auto design features. The F90 model, launched in 2000, was considered the model that most defined the design of future Jura machine generations. ${ }^{17}$

Beyond its design, partners were chosen for selective features, or elements, of its coffee machines. One was for the water filtration mechanism installed in every Jura machine.

Jura's supplier and partner, Acquis, a Swiss-based filtration specialist, designed the CLARIS filter cartridge especially for Jura machines in such a way that the resulting coffee quality would be consistent, independent of the water source used. Jura did not believe that it made sense to develop its own filter. Instead, the company aimed at collaborating with the best in the field and having that partner produce a custom-made filter for its machines. The same approach was used for other machine elements. The role of design was also core to Jura's strategy. The company was at the forefront of detecting the trend of coffee machines becoming an aspirational product for high-end customers. ${ }^{18}$

Jura had originally produced all of its home appliances and moved to a focus on design and marketing only later in its history; the company offers an example of extreme, or multilevel, focus. Not only did the company focus on a unique market space, namely the automated espresso machines for home use in the top-line segment, but it also honed in on the value chain concentration-the key tasks of designing and marketing. This represented a form of focus on multiple levels and allowed the company to concentrate its resources on a very narrow set of activities, or tasks, aimed at a very narrow market segment. At Sécheron, management referred to this approach as "task focus."

\section{Reflections}

The experience of the 36 SMEs demonstrates the importance of manufacturing in the firm's ultimate success. The vast majority, in fact 34 of the firms, owned their manufacturing assets even though their involvement could be anywhere from full integration to assembly only. The extent of manufacturing integration depended on the importance of proprietary production steps. If the proprietary steps were less important, or if there were no particular manufacturing skills involved, the companies moved toward assembly only or, in two instances, availed themselves of external contract manufacturers. When the latter was the case, the companies tightly controlled the engineering, quality, and design functions, while the sourced manufacturing components, or elements, remained proprietary to the originating company. As companies moved toward the lower end of the value-added chain

\footnotetext{
${ }^{17}$ Ibid.

${ }^{18}$ Ibid.
} 
activities, the role of marketing increased versus that of engineering, design, and quality control, as did the necessary skill sets. All of the companies maintained a close connection to production.

Open Access This chapter is licensed under the terms of the Creative Commons Attribution 4.0 International License (http://creativecommons.org/licenses/by/4.0/), which permits use, sharing, adaptation, distribution and reproduction in any medium or format, as long as you give appropriate credit to the original author(s) and the source, provide a link to the Creative Commons license and indicate if changes were made.

The images or other third party material in this chapter are included in the chapter's Creative Commons license, unless indicated otherwise in a credit line to the material. If material is not included in the chapter's Creative Commons license and your intended use is not permitted by statutory regulation or exceeds the permitted use, you will need to obtain permission directly from the copyright holder.

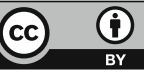

